\title{
SERVIÇO DE APOIO A DISTÂNCIA AO PROFESSOR EM SALA DE AULA PELA TV DIGITAL INTERATIVA
}

\author{
Sergio Ferreira do Amaral \\ Luciana Ozello Baratti \\ Daniel Moutinho Bataca \\ João Henrique de Augustinis Franco \\ José Manuel Martin Rios \\ Amilton da Costa Lamas

\section{Resumo}

Este é um artigo de um projeto em andamento desenvolvido em parceria com a Diretoria Técnica de Serviços do CPqD Telecom \& IT Solutions e a Faculdade de Educação da UNICAMP, que objetiva estabelecer um serviço de apoio a distância aos professores em sala de aula em 03 Escolas da região de Barão Geraldo em Campinas/ SP , para utilizar a TV Digital Interativa como ferramenta de busca e desenvolvimento de conteúdo multimídia interativo nas práticas pedagógicas. Fundamentalmente esta ferramenta será de fácil uso por utilizar como terminal de escolha e exibição um televisor colocado nas salas de aula das escolas e controlado por controle remoto. O professor poderá interagir com o conteúdo exibido no televisor de modo a obter uma programação não linear que se desenvolverá conforme o seu projeto pedagógico. As principais características do serviço são a facilidade de uso, fornecimento a distância de material multimídia interativo, baixo custo de implantação e grande área geográfica de cobertura, proporcionada pela disponibilidade quase total de sinal de televisão no território nacional. Este serviço é parte de um conjunto de serviços de teleducação que estão sendo desenvolvidos para o futuro Sistema de TV Digital terrestre que será implantado no Brasil.

\section{Palavras-chave}

Educação a distância; TV digital interativa; Novas tecnologias aplicadas na educação; Tecnologia da informação e comunicação.

\section{DISTANCE SUPPORT SERVICE TO TEACHEARS IN THE CLASSROOM THROUGH INTERACTIVE DIGITAL TV}

\begin{abstract}
This is an article of a developed in progress project in would seem the Direction Technique of Services of the CPqD Telecom \& IT Solutions and the College of Education of the UNICAMP, that objective in the distance to establish a support services to the teacher in classroom in 03 Schools of the region of Barão Geraldo in Campinas, SP, to use the Interactive Digital TV as a search tool and practical development of interactive multimedia content in the pedagogical practical ones. Basically this tool will be easy to use as a terminal of choice and exhibition a television set placed in the school's classrooms and controlled for remote control. The teacher be able to interact with according to the content shown in the television set in order to get a non linear programme that will develop this pedagogical project. The main services characteristics are the easiness of use, supply of the interactive at distance multimedia material, low cost of implantation and covering of a great geographic area, for the almost total availability of signal of television in domestic territory. This service is part of a set of TV-education services that are being developed for the coming System of terrestrial Digital TV that will be implanted in Brazil.
\end{abstract}

\section{Keywords}

Distance Education; Interactive Digital TV; New Technologies applied in Education; Infomation and Communication Technology 


\section{INTRODUÇÃO}

O Brasil tem aproximadamente 55 milhões de estudantes que estão no ensino básico (creche, pré-escola, alfabetização, ensino fundamental, ensino médio e médio profissionalizante, educação especial e educação de jovens e adultos), em cerca de 214 mil estabelecimentos de ensino públicos e privados. A maioria (87,6\%) está matriculada na rede pública. Se considerado apenas o ensino fundamental, são 90,8\% dos alunos na rede pública.

Hoje o Brasil possui 2,4 milhões de funções docentes na educação básica, destes 259 mil são professores de pré-escola, 809 mil de $1^{\text {a a }} 4^{\text {a }}$ série, 801 mil de $5^{\text {a a }} 8^{\text {a }}$ série e 468 mil no ensino médio ${ }^{1}$

Soluções relacionadas à Educação a Distância (EAD) podem ser vistas como uma grande oportunidade para a diminuição do problema educacional, pois além de possibilitar o acesso à educação para toda a população que atualmente não possui este acesso, ainda proporciona uma redução de custos, principalmente com relação à infra-estrutura.

Atualmente, a televisão possui o potencial de instrumento de apoio para a formação da população por estar presente em cerca de $88 \%$ dos lares brasileiros e possuir cobertura nacional. Além disso, a familiaridade que a população tem com a TV pode facilitar a adaptação ao uso desse aparelho para outras finalidades além do simples ato de assistir passivamente à programação. As mudanças no sistema escolar em função da chegada das novas tecnologias do conhecimento nos indica a necessidade de estudar a relação entre comunicação e educação de modo interdisciplinar, pois, os atuais estudiosos dessas áreas estão procurando resgatar a unidade intrínseca destes tratados que nem sempre se encontraram unidos.

O consumo das novas tecnologias de comunicação, em especial da Internet e da televisão são uma realidade inquietante, não só pela quantidade de tempo que diariamente são dedicados a estes meios, pelos diversos setores da sociedade, mas também, pelos valores 
das mensagens transmitidas. Hoje em dia, praticamente tudo é visto pela tela da televisão ou pela tela do computador. Assim, é necessário que a instituição escolar esteja preparada para educar com e para os meios. A educação terá de formar pessoas que irão enfrentar um mundo diferente do nosso, o digital. Consequentemente, terá que fazer com que estas pessoas sejam competentes na utilização e manejo das novas tecnologias.

O CPqD e a Faculdade de Educação da Unicamp, antecipando-se à esperada difusão da TV Digital, estão desenvolvendo tecnologias de serviços para esta plataforma de comunicação. Em função da sua importância, a teleducação, telemedicina e a inclusão digital foram escolhidas como temas principais. As tecnologias desenvolvidas não se limitam, no entanto, a somente essas aplicações, elas poderão e deverão ser aplicadas no desenvolvimento de novos serviços que abordem outros temas, tais como entretenimento, mensagem, comunicação, transação e informação. Os dados na forma de vídeo, áudio, gráfico e texto poderão utilizar a futura plataforma de TV Digital para serem acessados, baixados, armazenados e vistos mais tarde, de forma que a TV possa ser um meio tão rico de acesso à informação quanto o computador pessoal.

O serviço apresentado neste artigo faz parte do Projeto de TV Digital Interativa que está sendo desenvolvido no $\mathrm{CPqD}$ com recursos do Fundo para o Desenvolvimento Tecnológico das Telecomunicações (Funttel). Este projeto é subdividido em três subprojetos, o primeiro de implantação de uma Estação de Serviços Experimentais, o segundo de desenvolvimento de serviços interativos para a TV Digital e o terceiro de desenvolvimento de serviços para a convergência da rede de radiodifusão com a rede de computadores (Internet). O serviço aqui apresentado faz parte do segundo sub-projeto, que envolve o desenvolvimento de um conjunto de serviços para a teleducação, listados a seguir:

- Serviço de Apoio ao Professor em Sala de Aula (SAPSA)

- Serviço de Apoio ao Estudante em Casa (SAEC)

- Serviço de Interação Pais-Escola (SIPE) 


\section{CARACTERIZAÇÃO DO AMBIENTE EDUCACIONAL}

A integração do sistema clássico de meios com o mundo das telecomunicações da informática e, em definitiva, com os avanços produzidos com a digitalização da informação fez surgir a nova televisão, ou melhor, a TV Digital.

O futuro parece nos conduzir inevitavelmente para o estabelecimento de redes baseadas na fibra óptica por onde circulam áudio, vídeo e dados, em pacotes condensados que permitirão a interatividade e o fim do consumo televisivo ingênuo e unidirecional. No ano de 2010, provavelmente, as televisões serão digitais, nos ocuparemos mais com a seleção e controle do bit, ou seja, com a informação. Estaremos diante de um meio diferente, poderemos ver e escutar as notícias ou ver uma partida de futebol quando desejarmos e, o mais importante estaremos diante de uma TV Interativa.

Consequentemente, se a programação televisiva vai ser digital a forma de acesso a ela e de controle também o será. O televisor parecerá mais a um computador que a um televisor. Concluímos então, que o conceito que temos hoje de um aparelho de televisão vai deixar de existir. Não se fabricarão televisores e sim computadores de diversos tamanhos alimentados com imensas quantidades de memórias e grande capacidade de processamento de informação.

A educação para o uso da TV Digital e Interativa encontra sua máxima expressão quando docentes e alunos têm a oportunidade de criar e desenvolver através dos meios suas próprias mensagens, Schaeffer (1990) diz que: "para ler as imagens, igual aos textos escritos, não se deve esquecer que é necessário aprender simultaneamente a escrever. A expressão através da TV Interativa, como estratégia motivadora e desmitificadora, requer, portanto, não apenas decifrar a linguagem da comunicação, mas sim servir-se dela".

Incorporando esta experiência, alunos e docentes podem perceber significativamente a construção da realidade que todo conteúdo mediático comporta. Esta faceta expressiva é fundamental para conseguir o objetivo de uma educação para os meios. Pérez Tornero (1994) diz que: "todos estes princípios de atuação - no sentido chomskiano e habermasiano - se reduzem em potenciar uma nova competência comunicativa.”. 
Sendo a TV Digital Interativa uma nova tecnologia, deve-se incorporar ao currículo escolar. Entretanto, para que isso aconteça com êxito, é preciso que seja superada a clássica e absurda rivalidade que os pais e os professores vêem na televisão considerando-a como uma inimiga da educação.

A TV Digital abre as portas, de uma maneira muito especial, para a alfabetização audiovisual permanente, possibilita e fomenta nos espectadores a capacidade de produzir e analisar suas próprias mensagens. Utilizando a TV desta forma, a educação estaria promovendo a intervenção social, potenciando uma educação dinâmica, cooperativa e solidária, e a partir de um conceito social de liberdade, estaria desenvolvendo a imprescindível formação para a cidadania.

O objetivo de ensinar e aprender através da TV Digital promete ser o meio de comunicação mais potente deste século, por tudo que já ressaltamos, consiste em ensinar a pensar a cultura mediática e reflexionar sobre a realidade. Para isto observa Masterman (1993):

\footnotetext{
É importante que o material audiovisual produzido não seja consumido inocentemente, mas sim seja lido de um modo crítico. Parece obvio que os professores de todas as disciplinas devem favorecer a técnica básica de alfabetização audiovisual consistente para relacionar as mensagens dos meios com os interesses políticos, sociais e econômicos de quem os produzem.
}

Se apropriando das novas tecnologias, que possibilitaram a digitalização da informação, a nova TV será Interativa e deixará de ser um veículo de comunicação unidirecional como aponta Silva (2000): "no sistema broadcast (difusão para a massa a partir de uma fonte geradora segundo o modelo Um todos), a tv não é interativa, é emissão

basicamente ".

Essa nova perspectiva comunicacional televisiva, altera a função cotidiana da televisão profundamente. Como sugere Lafrance (1994):

a relação que (a velha televisão) estabelecia com o espectador era de tipo vertical, paternalista e autoritária: lhe ensinava algo, lhe informava de [...] lhe apresentava um espetáculo.[...] Em resumo, as emissões estavam marcadas pelo ritmo do acontecimento, da festa. Consumo quase sagrado, ritualização da vida coletiva entorno de acontecimentos excepcionais o convertidos em excepcionais pelo ufanismo mediático. 
A TV Interativa muda essa situação e, promove o encontro do telespectador com a televisão, que não é mais detentora absoluta da emissão.

A televisão, na sociedade capitalista segundo os teóricos críticos da escola de Frankfurt é vista como um agente socializador e formador de opinião. O homem, no modelo tradicional de comunicação (emissor-mensagem-receptor), torna-se objeto e a sua finalidade última é o consumo. A introdução da interatividade na TV, coloca em crise este modelo, já que o receptor não será mais um receptor passivo e, sim um receptor ativo.

Admitir tal realidade encaminha-nos para o futuro do uso didático da TV na escola. A interatividade, característica dos novos meios, adquire um sentido pleno no terreno educativo. Um uso criativamente pedagógico e crítico dos meios somente é possível em uma escola que transforme seu modelo transmissivo centrado em uma seqüência linear e unidirecional, professor-aluno. Este modelo "instrutivo", é o responsável em boa parte pela resistência dos professores a novos modelos de ensino-aprendizagem.

Não há rivalidade entre meios e educadores, como não há entre linguagem textual e audiovisual. No entanto, muitos professores ainda não se conscientizaram que sua função como fonte única, direta e primaria de informação desapareceu. Já não há lugar, em palavras de Kaplún (1997), "para essa educação memorística, mecânica, repressiva, divorciada da vida, que deixa as crianças em uma atitude passiva e amorfa que só engendra fracassos".

Educar através da nova televisão, portanto, vai exigir que educadores e comunicadores afrontem três grandes tarefas: a compreensão intelectual do meio, a leitura crítica de suas mensagens e a capacitação para a utilização livre e criativa.

Os caminhos entre a nova TV que será interativa não são contrários aos caminhos da escola. Estes caminhos se cruzam e se revelam na procura de novas aprendizagens, do entendimento e da vida. 


\section{TV DIGITAL INTERATIVA ${ }^{2}$}

“Televisão Interativa” é um termo para o qual não existe ainda uma definição formal. Entretanto, o seu conceito existe desde a década de 60, como testemunham os livros e filmes de ficção científica da época, segundo os quais a televisão do futuro seria capaz de exibir exatamente a informação desejada pelo usuário, no momento desejado, e atendendo a um comando meramente vocal, quando não telepático. Seria uma contraposição à televisão convencional, na qual as pessoas assistem passivamente à programação que está sendo transmitida, sem nenhum controle sobre o conteúdo da informação exibida, exceto a possibilidade de troca de canais.

A televisão interativa que hoje se descortina ainda está longe de ser esse objeto mágico e onisciente, esse "servo eletromecânico" dos contos de ficção de meio século passado. Entretanto, com a digitalização, a televisão está em vias de deixar de ser um objeto de consumo meramente passivo, passando a ser possivelmente um mecanismo através do qual o usuário poderá ter acesso a uma maior diversidade de informações, com uma interface mais rica e complexa.

A TV Digital Interativa, embora seja uma sucedânea da televisão convencional, possui um conjunto de características que a diferencia significativamente dessa, motivo pelo qual fazse necessária a introdução de alguns conceitos e termos mais adequados a esse novo ambiente.

Na televisão convencional, canal e programação se confundem, pois às vistas do usuário, referem-se à mesma coisa. Na Televisão Digital, entretanto, elas referem-se a coisas distintas. Canal é o meio através do qual as programações são transmitidas. No caso do Brasil, em radiodifusão, “canal” refere-se a uma janela de freqüências com largura de 6 $\mathrm{MHz}$, localizada na faixa de VHF ou UHF. Por exemplo, o canal 2 refere-se à janela de 54 a $60 \mathrm{MHz}$, o canal 3 de 60 a $66 \mathrm{MHz}$, etc. Já o conteúdo transmitido através desse canal é denominado de programação. 
Na televisão convencional, a programação é composta por um conjunto seqüencial e ininterrupto de programas, incluindo os intervalos comerciais. Todo programa está associado a uma programação, e vice-versa, assim como toda programação está inequivocamente associada a um canal e vice-versa.

Na Televisão Digital, embora o usuário possa estar assistindo a uma seqüência ininterrupta de informações, a composição das programações não é tão estanque.

A Programação “A”, por exemplo, é composta dos Programas 1, 4, 6 e 7. A Programação “B” é composta pelos programas 2, 6 e 8. Já a Programação “C” é composta pelos Programas 3, 5, 6 e 7. Ou seja, inexiste uma relação biunívoca entre programas e programações, como ocorre na televisão convencional.

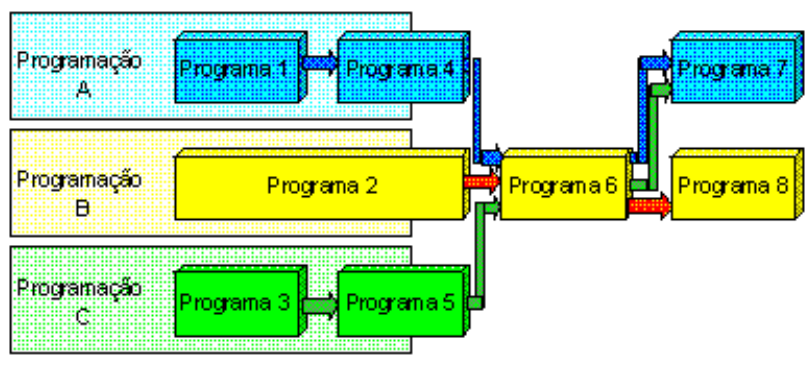

Figura 1 - Programas e programações em ambiente de TV Digital

Um programa de televisão convencional é composto de imagens e sons. Já um programa de televisão digital, pode ser composto por imagens, sons e dados, estes últimos referindo-se a textos, gráficos, ícones, programas executáveis ou quaisquer outros tipos de informações. Cada um desses “componentes” de informação é denominado de elemento de informação.

Os elementos de informação de natureza visual (imagens, ícones), ao serem reproduzidos na tela do televisor, podem atuar como uma interface "clicável”, ou seja, receberem comandos do usuário, convertendo tal instrução em alguma ação. Denomina-se de objeto clicável a todo elemento que possua tal característica. A Televisão Digital Interativa é um 
sistema capaz de receber e executar comandos do usuário. Tais comandos são geralmente (mas não necessariamente) vinculados a algum objeto clicável.

As possibilidades criadas pela tecnologia digital, aliadas à natureza aleatória de como os usuários podem acionar os comandos clicáveis, introduz uma nova característica aos programas de TV Digital Interativa, que podem diferenciá-los significativamente dos programas de televisão convencional. Nestes, os programas são lineares, ou seja, existe um ponto de início, um ponto de término e um único enredo interligando os mesmos. Já os programas de Televisão Interativa, conforme ilustrado na Figura 2, podem ser altamente não-lineares, significando com isso que eles podem ter diversos pontos de entrada e saída, e diversos roteiros interligando os mesmos.

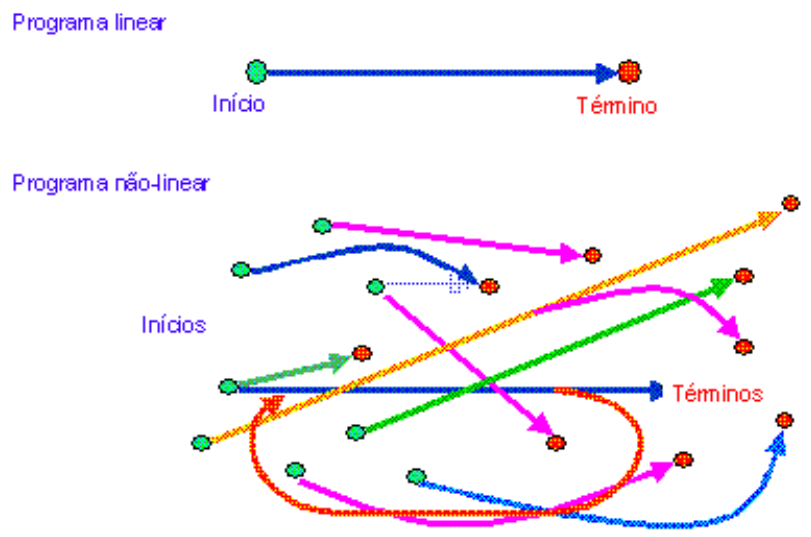

Figura 2 - Programa linear da televisão convencional vs. programa não-linear da televisão digital interativa

Essas características da Televisão Digital Interativa trazem uma série de oportunidades, como o pay-per-view, o vídeo sob demanda, guia eletrônico de programação (EPG), acesso a maiores informações sobre a programação, teleeducação e acesso à Internet.

\section{TV DIGITAL COMO FERRAMENTA PARA O ENSINO}

Uma das principais dificuldades, na utilização da televisão como meio de transmissão de conhecimento, é a visão majoritária que este é um meio de difusão de entretenimento e não de educação. Apenas 31\% dos brasileiros assistem freqüentemente a programas ou canais educativos na TV e os principais motivos alegados por quem não assiste esse tipo de programa/canal é a falta de interesse (31\%), falta de tempo para assisti-los (25\%) e o fato

(c) Revista Digital de Biblioteconomia e Ciência da Informação, Campinas, v. 1, n. 2, p. 53-70 , jan../jun. 2004 - ISSN: 1678-765X. 
do programa passar muito cedo (25\%). Além disso, os programas educacionais são considerados “chatos” por muitas pessoas, não se tornando um atrativo capaz de levar lazer e entretenimento. ${ }^{3}$

A TV Digital, por sua vez, representa uma revolução, combinando as características tradicionais da televisão analógica com as potencialidades do computador pessoal e com o impacto da Internet na sociedade. Além disso, ao utilizar parte significativa da infraestrutura existente da televisão analógica, se beneficiará do alto grau de penetração dessa tecnologia.

Para a população a TV Digital incorporada ao dia-a-dia implicará em mudanças de hábitos, nova relação de consumo e outras alterações que serão provocadas ao longo da convivência com esta nova tecnologia, pois além do conhecido aparelho de TV e controle remoto, a TV apresentará novos componentes de interatividade, estabelecendo novos relacionamentos e novas formas de comunicação, abrindo mundos e possibilidades antes desconhecidos e limitados.

O uso da TV na escola possibilita o acesso dos alunos a trechos de vídeos, filmes, entrevistas ou quaisquer tipos de programas que podem agregar valor ao aprendizado, trazendo para dentro da sala de aula o mundo em que o aluno vive, seu cotidiano e a linguagem audiovisual na qual já está familiarizado, permitindo, assim, maior fluidez do aprendizado já que a leitura da imagem é mais livre e menos rigorosa que a palavra escrita. Com a TV interativa a utilização desse conteúdo em sala de aula se tornará mais interessante na medida em que não será um processo linear, o professor poderá navegar por diferentes conteúdos educacionais, conforme surjam dúvidas e comentários dos alunos, propiciando maior envolvimento tanto dos alunos quanto dos professores durante a aula ${ }^{4}$.

Um importante obstáculo à incorporação dessa nova tecnologia pelos professores no cotidiano escolar é a resistência à mudança no modo de ministrar as aulas, causada pela 
adoção de mais uma ferramenta em sala de aula. Porém, este desafio não pode ser considerado um obstáculo intransponível e para isto a capacitação dos professores é essencial. Outro ponto que, se não adequado, pode dificultar a incorporação da nova tecnologia, é a interface da ferramenta com o usuário, que deve ser simples, focada na facilidade e rapidez do uso e na busca de informações.

\section{SERVIÇO DE APOIO A DISTANCIA AO PROFESSOR EM SALA DE AULA}

Para o desenvolvimento de um serviço, utilizamos uma metodologia dividida em quatro fases. Na primeira, realiza-se o planejamento do serviço, onde é feita uma descrição funcional detalhada, um estudo da cadeia de valor e uma análise de viabilidade econômica. Na segunda fase, é feita a implementação com uma descrição técnica detalhada do serviço, sua confecção e teste dos aplicativos em laboratório. Na terceira fase, é realizada a implantação do serviço na plataforma de oferta e na última o serviço é colocado em operação e pesquisas de opinião são efetuadas com os usuários de modo a avaliar a aceitação e mapear as características que devem ser alteradas no serviço para a satisfação dos consumidores.

A seguir será apresentada a descrição, realizada na fase de planejamento, do Serviço de Apoio ao Professor em Sala de Aula (SAPSA), que estamos desenvolvendo. O objetivo do SAPSA é permitir que seus clientes: o MEC e as Secretarias de Educação Estaduais e Municipais, ou as redes de escolas privadas, obtenham resultados mais efetivos na transmissão de conhecimento aos alunos das escolas. ${ }^{5}$

Para tanto a escola passará a contar com uma ferramenta de tecnologia moderna: a Televisão Digital Interativa em sala de aula. Acredita-se que os métodos de ensino aplicados atualmente poderão ser aprimorados com a inserção da televisão no ambiente da sala de aula. Esse aparelho passaria a ser uma ferramenta importante de apoio ao professor durante a aula, num processo semelhante ao da introdução dos livros didáticos em passado recente. 
O uso do serviço exige que o professor tenha apenas uma ligeira familiaridade com a utilização de aparelho de TV com controle remoto. Cada sala de aula na escola contará com um aparelho de televisão. O aparelho será acionado pelo controle remoto, semelhante ao convencional, permitindo que o professor tenha acesso a material educacional multimídia, enriquecendo, desta maneira, sua aula. Por ser baseado em um aparelho de TV Digital Interativa, o SAPSA permitirá que o professor obtenha esse material a qualquer instante no decorrer de sua aula ou, se preferir, antes da aula, ficando então armazenado à sua disposição.

O aparelho de TV Digital Interativa nada mais é do que um aparelho convencional de televisão ao qual é conectada uma caixa conhecida como Decodificador. Esse decodificador se encarregará de transformar os sinais digitais, captados por uma antena comum, em sinais apropriados para o aparelho de TV convencional. O sistema é semelhante às plataformas de televisão por assinatura via satélite. No futuro esse decodificador poderá ser integrado ao monitor de televisão, se assim se desejar.

O professor utilizará o serviço de maneira semelhante à navegação por um guia eletrônico de programação (EPG, do inglês Eletronic Program Guide) existente atualmente nos sistemas de TV por assinatura via satélite. Mas ao invés de navegar apenas por canais de televisão, navegará também por um guia de conteúdo educacional com endereçamentos do tipo Matemática, História, etc. Nesses endereços estará disponível o material educacional referente a cada assunto.

O material educacional multimídia será constituído por vídeos de curta duração, por animações, textos e gráficos, ou outras telas como a exibida na Figura 3 para ilustração. As telas acessadas pelo EPG conterão, quando necessário, hyperlinks para a navegação ao estilo Internet ou como em enciclopédias para computadores pessoais, utilizando botões existentes no controle remoto para esse fim. O serviço será capaz de realizar buscas, procurando localizar materiais já disponibilizados em períodos anteriores, ou utilizados em outras ocasiões pelo professor para a preparação da aula. 
O conteúdo a ser exibido será constituído principalmente, e majoritariamente, por produções especialmente produzidas para a finalidade de educação, selecionadas e organizadas para sua posterior exibição em sala de aula.

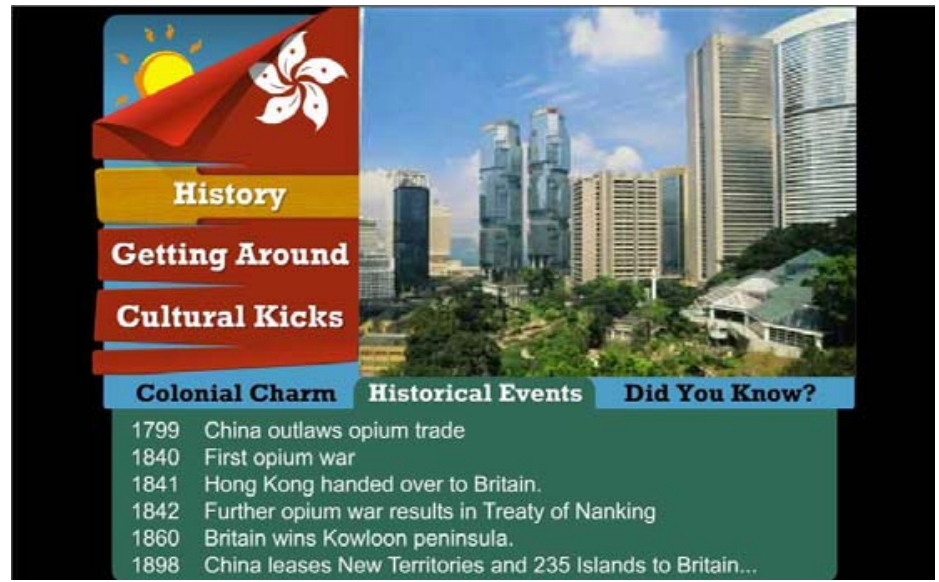

Figura 3 - Exemplo de tela para a navegação na TV

Uma das características principais do SAPSA é a recepção por radiodifusão terrestre e não através de cabos coaxiais ou via satélite, como na TV por assinatura, diminuindo-se assim os custos de acesso para cada escola e ampliando-se o universo de escolas atendidas, devido a grande cobertura geográfica da televisão aberta no Brasil.

O sistema básico exige ao menos uma conexão a antena comum para o equipamento de sala da aula e da sala de professores, onde o professor poderá buscar material multimídia transmitido por radiodifusão para elaboração das suas aulas. Será necessária também ao menos uma linha telefônica à disposição em cada escola para o professor efetuar, através da televisão, a requisição do material desejado.

Doravante, quando estamos se referindo a "Sala de Professores", esta é dotada de equipamento apropriado para o acesso ao serviço pelos professores, podendo ser a atual sala de professores das escolas ou outra sala devidamente adaptada para essa finalidade. $\mathrm{O}$ objetivo dessa sala é propiciar um ambiente fora da sala de aula, e do horário de aulas, onde os professores possam preparar o material a ser utilizado em aula, em conjunto ou individualmente, se assim desejarem. Imagina-se que, inicialmente, esse ambiente será utilizado para o treinamento de professores e monitores, de maneira a propiciar um aprendizado suave e contínuo sobre o SAPSA. 
A Figura 4 a seguir, apresenta uma visão esquemática do serviço. Tem-se o fluxo de informação entre alunos e o repositório de conteúdo, com a mediação do professor, e a figura de um administrador responsável pelo gerenciamento do conteúdo.

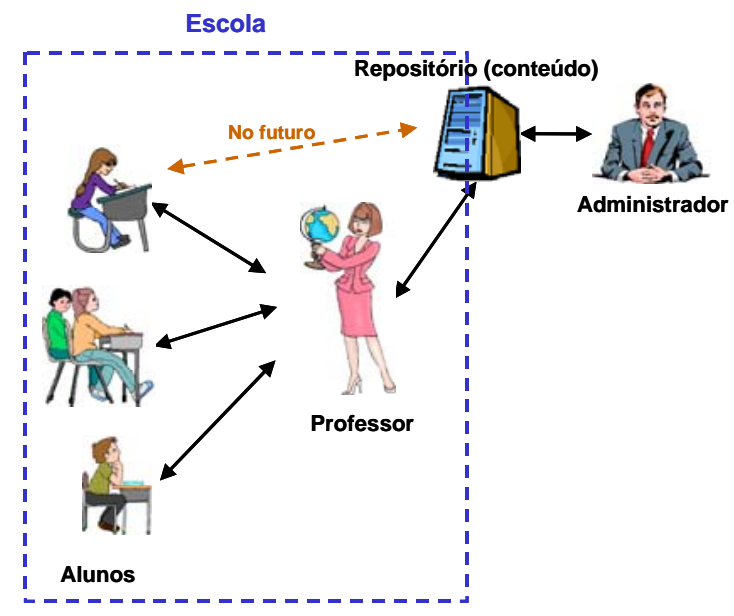

Figura 4 - Representação esquemática do fluxo de informação no serviço SAPSA

Para efeito de teste, inicialmente o SAPSA será disponibilizado para um público limitado através da Estação de Serviços Experimentais a ser implantada no CPqD. Esta Estação Experimental fornecerá sinal a diversos públicos-alvo da região que circunvizinha o $\mathrm{CPqD}$ principalmente para o distrito de Barão Geraldo localizado em Campinas, SP. A utilização da infra-estrutura da torre de recepção do laboratório de antenas do CPqD permitirá uma cobertura adequada desta região. Esta região é particularmente interessante para os testes de validação dos novos serviços, já que conta com uma população econômica e socialmente diversificada, representativa dos diversos públicos-alvo com os quais se pretende trabalhar, servindo para caracterizar condições diferenciadas de oferta de novos serviços.

A Faculdade de Educação da Unicamp conjuntamente com três escolas de ensino fundamental do distrito de Barão Geraldo e o CPqD estão trabalhando na especificação das funcionalidades do serviço. Alem disso, a Faculdade de Educação e escolas desenvolverão o conteúdo educacional voltado para os alunos da quarta série do ensino fundamental. Para a preparação deste conteúdo multimídia o CPqD implantará um estúdio de produção para uso dos professores e alunos envolvidos no projeto. Também, serão disponibilizados para as escolas envolvidas os equipamentos de recepção, necessários em sala de aula, para a 
exibição do conteúdo e decodificadores em algumas residências do distrito principalmente aquelas onde morem crianças que estejam envolvidas no projeto.

\section{CONCLUSÃO}

Apresentou-se um serviço de apoio aos professores que está em desenvolvimento no CPqD para a oferta de material multimídia interativo nas salas de aula. A solução proposta vai utilizar a TV Digital Interativa terrestre como meio para o fornecimento das informações.

Devido ao fato que este projeto já nasce com uma elaboração participativa dos próprios professores das 03 Escolas e com o envolvimento efetivo dos alunos, tudo leva-nos a crer que tenhamos de fato uma concretização do desenvolvimento de um modelo de aprendizagem mediatizada pela TV Digital.

A educação será a chave para resolver problemas econômicos e entre culturas, as gerações mais jovens é que precisarão encontrar soluções. Estamos todos cientes de que temos a responsabilidade de oferecer aos alunos de hoje as habilidades que eles precisarão para ter sucesso no ambiente de trabalho que, cada vez mais, baseia-se nas informações. Essas habilidades certamente incluem saber utilizar computadores; mais importantes ainda são as habilidades pessoais e sociais que devem ser desenvolvidas.

Os professores envolvidos com o projeto, estarão descobrindo, inventando e compartilhando tipos de práticas e programas em suas próprias salas de aula que ilustram a verdadeira reforma educacional. E, como a TV Digital Interativa é uma ferramenta de comunicação incrivelmente eficiente, esses professores estarão procurando uns aos outros, compartilhando suas experiências e organizando-se de novas maneiras nas escolas.

Um desenvolvimento importante no pensamento atual sobre a educação é que agora reconhecemos a necessidade de os alunos desenvolverem habilidades de aprendizagem por toda a vida. 
Os alunos aprenderão a definir suas necessidades de aprendizagem, encontrar informações, estimular seu valor, construir a sua própria base de conhecimento e comunicar suas descobertas.

Para valorizar e permitir este referencial “aprendendo a aprender” também será previsto a disponibilização do laboratório de produção para uso dos alunos das 06 escolas e da comunidade (pais e irmãos dos alunos) no período noturno. Os próprios alunos poderão orientar ações no uso da TV Digital aos seus familiares.

Espera-se que devido a facilidade de uso e familiaridade da televisão o serviço seja aceito pelos professores para o apoio a sua tarefa em sala de aula de levar conhecimentos aos seus alunos.

\section{NOTAS DE FIM:}

$\mathbf{H}$

[1] MINISTÉRIO DA EDUCAÇÃO. Censo Escolar 2002. Disponível em: $<$ Hhttp://www.educacao.gov.br/H>. Acesso em: 27.dez. 2002.

[2] TOME, T.; BARATTI, L.; RAFAEL R.; GEROLAMO, G.: “Atividade I - Levantamento do Estado da Arte em TV Interativa”. Campinas: CPqD, 2002. (Relatório técnico).

[3] BARATTI, L.; GEROLAMO, G.; NASCIMENTO, M. G.: "Atividade III - Mapeamento do perfil da população brasileira”. Campinas: CPqD, 2002. (Relatório técnico).

[4] ESCOLA DO FUTURO. "Relatório final referente ao Pré-Projeto da Experiência Piloto de Teleducação sobre Plataforma de TV Digital Interativa". Comunicação privada, fevereiro 2003.

[5] RIOS, J. M.; FRANCO, J. H. “Atividade V - Caracterização de Modelos de Negócios em Ensino a Distância - RDP para o Serviço de Apoio ao Professor em Sala de Aula - SAPSA". Campinas: CPqD, 2002. (Relatório técnico).

\section{REFERÊNCIAS}

AGUADERO, F. La sociedad de la información. Madrid: Acento Editorial, 1997.

CASTELLS, M. La era de la información: economía, sociedad y cultura. Madrid: Alianza Editorial, 1997.

DELORS, Jaques et al. La educación encierra un tesoro. Madrid: UNESCO y Santillana, 1996.

ECHEVERRÍA, J. Telepolis. Barcelona: Destino, 1994. 
FERRÉS, Joan. Televisión e educación. Barcelona: Editorial Paidós, 1996.

FREIRE, P. Educação como prática da liberdade. Rio de Janeiro: Paz e Terra, 1983.

FREITAG, B. Escola, estado e sociedade. São Paulo: Editora Moraes, 1986.

INTERCOM - Revista Brasileira de Comunicação, São Paulo, v. 16, n. 01, jan/jun. 1993.

KAPLUN, M. Pedagogía de la Comunicación, en Voces y Culturas, n 11/12, p. 69-88, 1997. Apud PÉREZ TORNERO, J. M. El desafío educativo de la televisión: para comprender y usar el medio. Barcelona: Paidós, 1994.

LAFRANCE, Jean-Paul. La televisión y su público: un contrato en proceso de renegociación permanente. Telos, n. 39, p. 14-25, Sept./ Nov. 1994.

LIMA, L de O. Mutações em educação segundo Mc Luhan. Rio de Janeiro: Vozes, 1971.

MARTÍN. A . G. Educación multimedia y nuevas tecnologías. Madrid :Ediciones de la Torre, 1997.

MASTERMAN, L. El futuro, en La enseñaza de los medios de comunicación. Madrid: Ediciones de La Torre, 1993.

PÉREZ TORNERO, J. M. El desafío educativo de la televisión: para comprender y usar el medio. Barcelona: Paidós, 1994.

SCHAEFFER, P. Incidencia de los media sobre la educación general en UNESCO: sobre el futuro de la educación hacia en año 2000. Madrid: Narcea, 1990.

SILVA, M. Sala de aula interativa. Rio de Janeiro: Quartet, 2000. 230p.

VILCHES, L. M. La televisión. Los efectos del bien y del mal. Barcelona: Paidós, 1993. 


\section{SERGIO FERREIRA DO AMARAL}

Professor Doutor da Faculdade de Educação da Universidade Estadual de Campinas - UNICAMP Coordenador do Grupo de Pesquisa TIC's da Área 2 - Educação, Ciência e Tecnologia.

e-mail: Hamaral@unicamp.brH

\section{LUCIANA OZELLO BARATTI}

Diretora Técnica de Serviços do CPqD

e-mail: Hlubaratti@cpqd.com.brH

\section{DANIEL MOUTINHO PATACA}

Diretor Técnico de Serviços do CPqD

e-mail: Hpataca@cpqd.com.brH

\section{JOÃO HENRIQUE DE AUGUSTINIS FRANCO}

Diretor Técnico de Serviços do CPqD

e-mail: Hfranco@cpqd.com.brH

\section{JOSÉ MANUEL MARTIN RIOS}

Diretor Técnico de Serviços do CPqD

e-mail: Himrios@cpqd.com.brH

\section{AMILTON DA COSTA LAMAS}

Diretor Técnico de Serviços do CPqD

e-mail: Hamilton@cpqd.com.brH

Artigo aceito para publicação em: 1/11/2003 